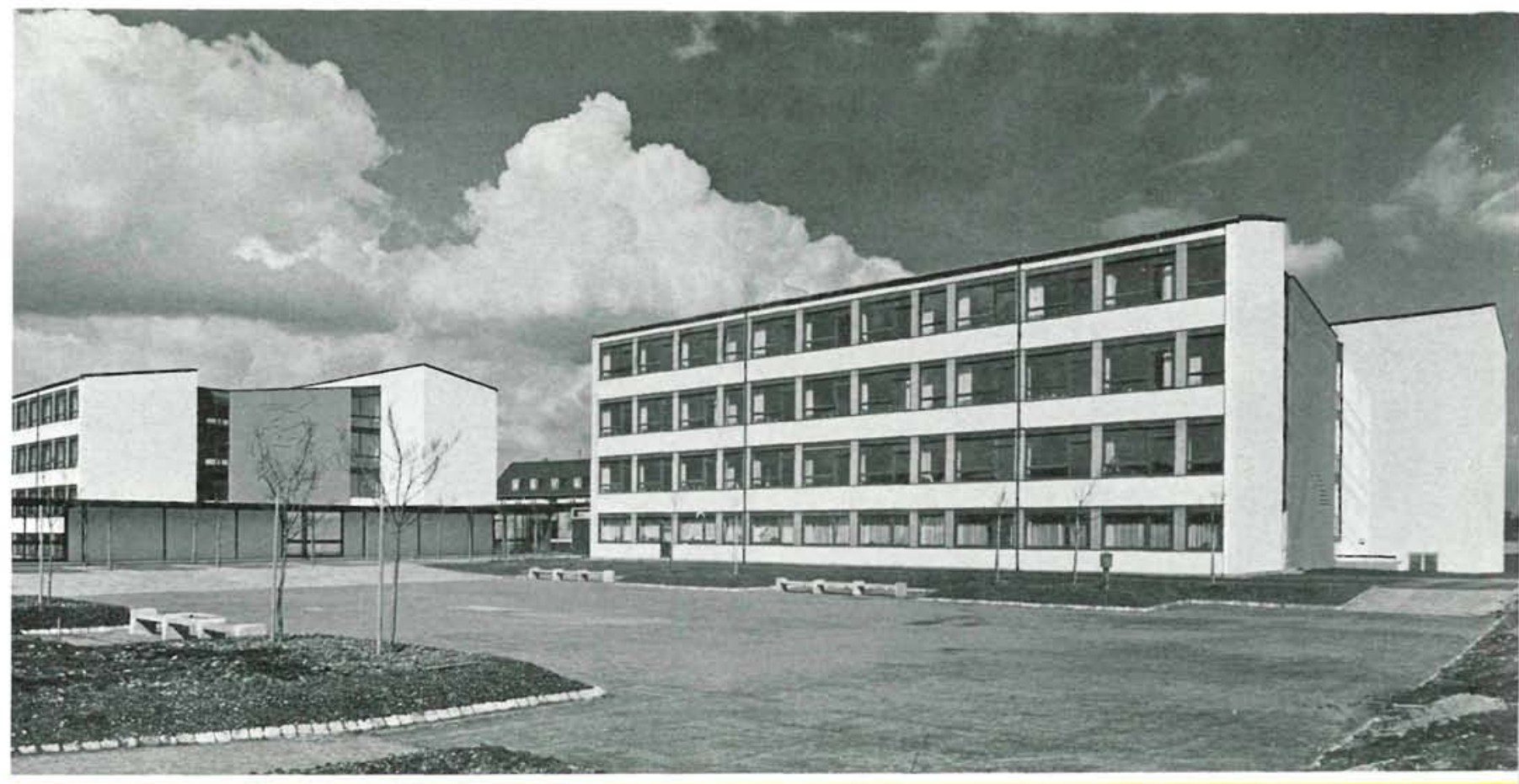

\section{Sin oppisis}

Formando un conjunto ópticamente independiente del paisaje urbanistico circundante ha sido construida esta Escuela, que consta de dos cuerpos de edificio - en los que se desarrollan las clases- enlazados mediante un paso de unión cubierto y un pasillo, al final del cual está el pabellón de música.

El patio de recreo y el campo de deportes determinan la situación de los gimnasios.

Todos los detalles interiores, el juego de volúmenes edifica. dos y su organización funcional colaboran eficazmente al logro definitivo de esta interesante construcción escolar.

\section{Bscuba}

\section{femenina de enseñanza media, en Munich - Alemania}

F. F. HAINDL, arquitecto BDA

$142-51$

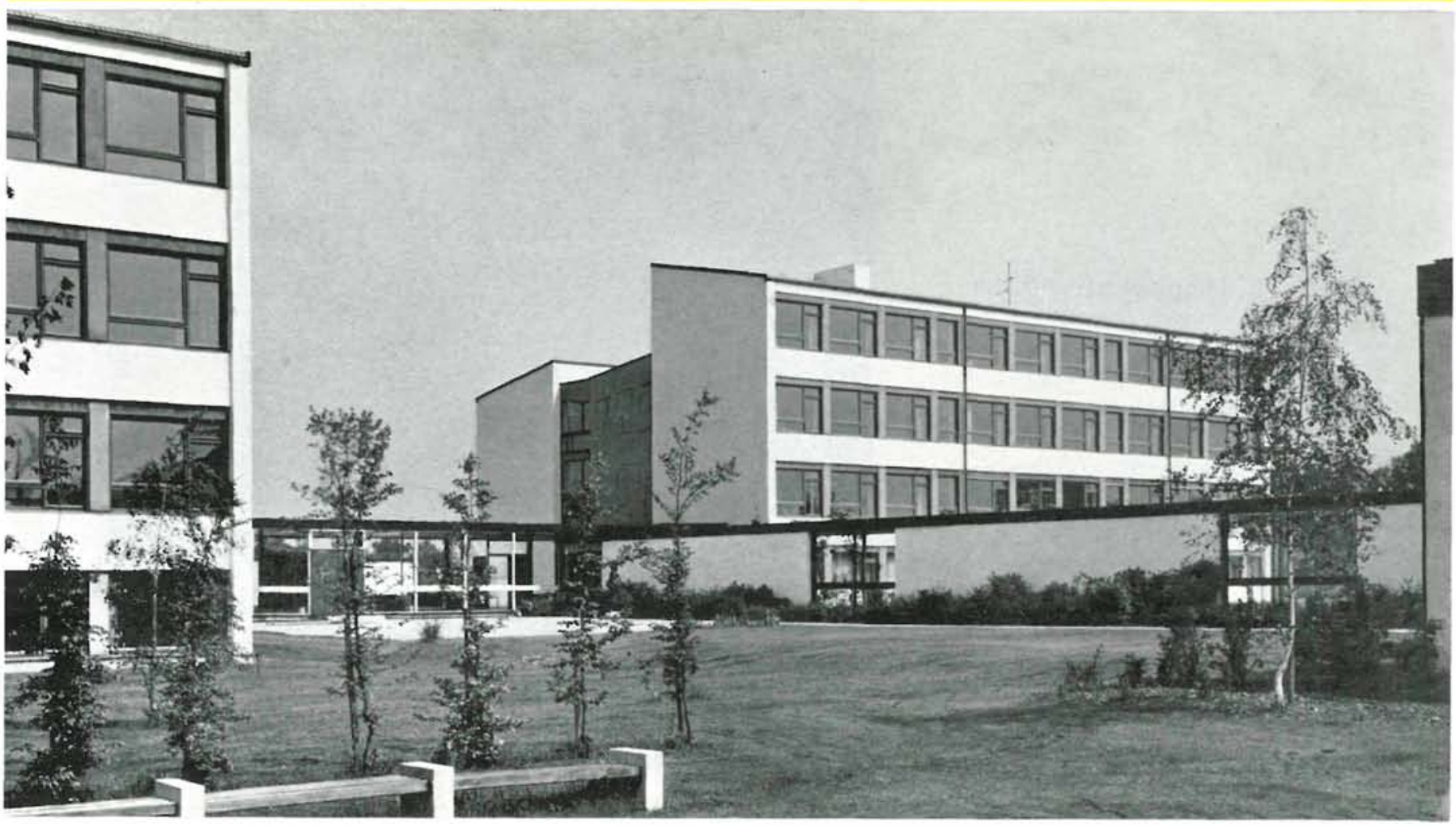




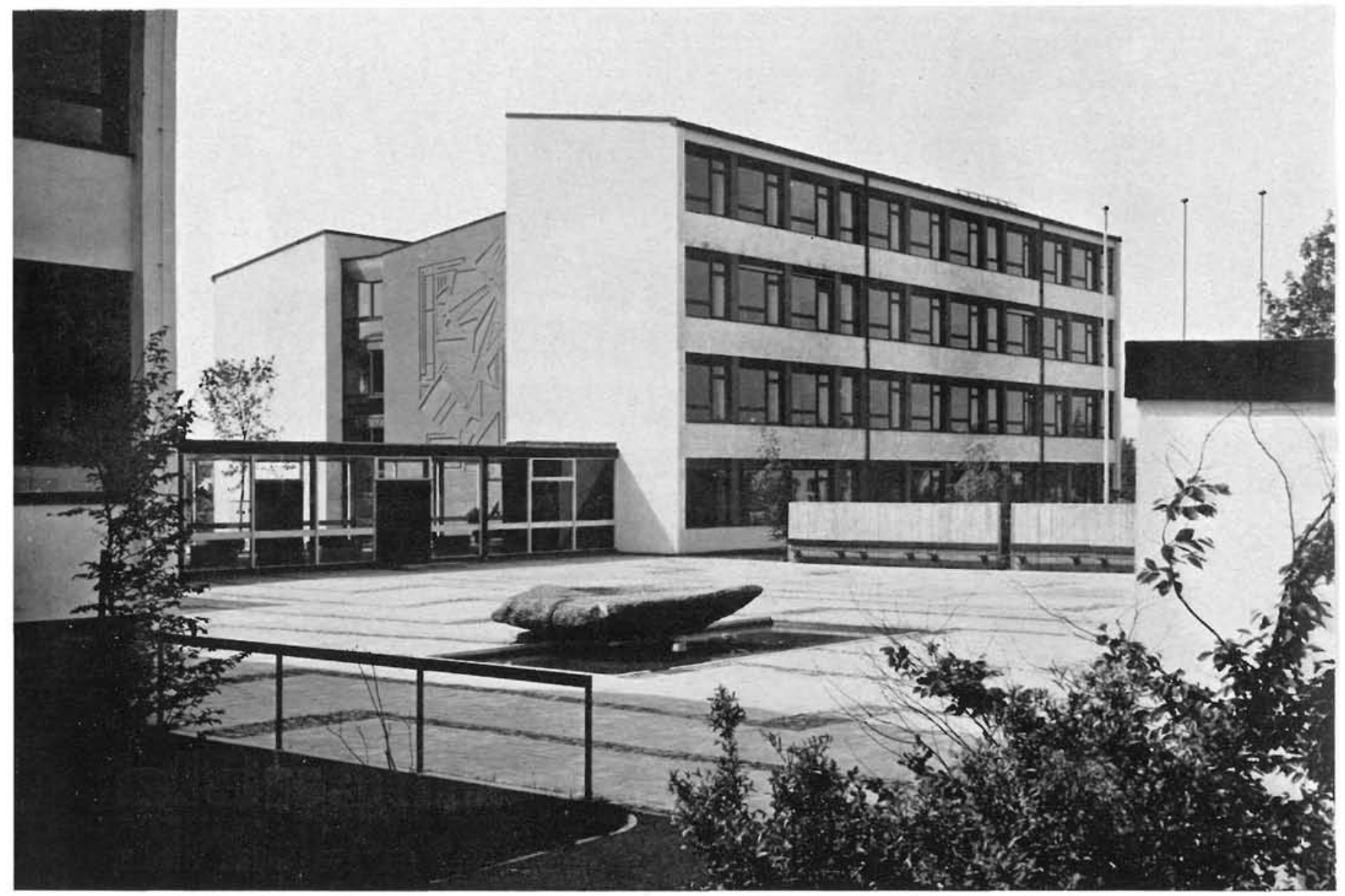

A pesar de que el paisaje circundante no ofrecía un gran interés, y las edificaciones existentes alrededor del terreno de la escuela no presentaban un atractivo especial, el arquitecto consiguió, mediante una disposición apropiada de los edificios proyectados, acertados efectos espaciales, logrando que el conjunto apareciese ópticamente independiente de la vecindad.

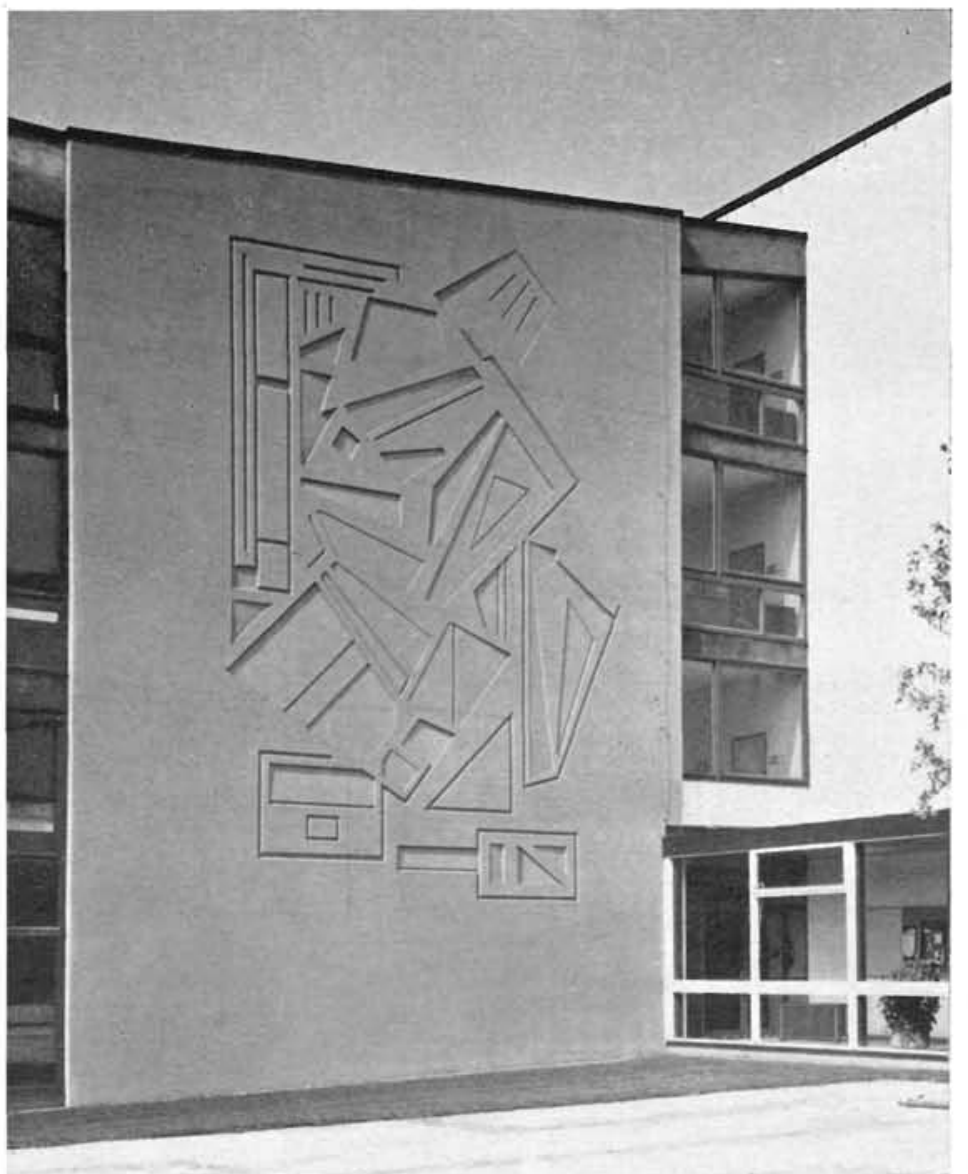




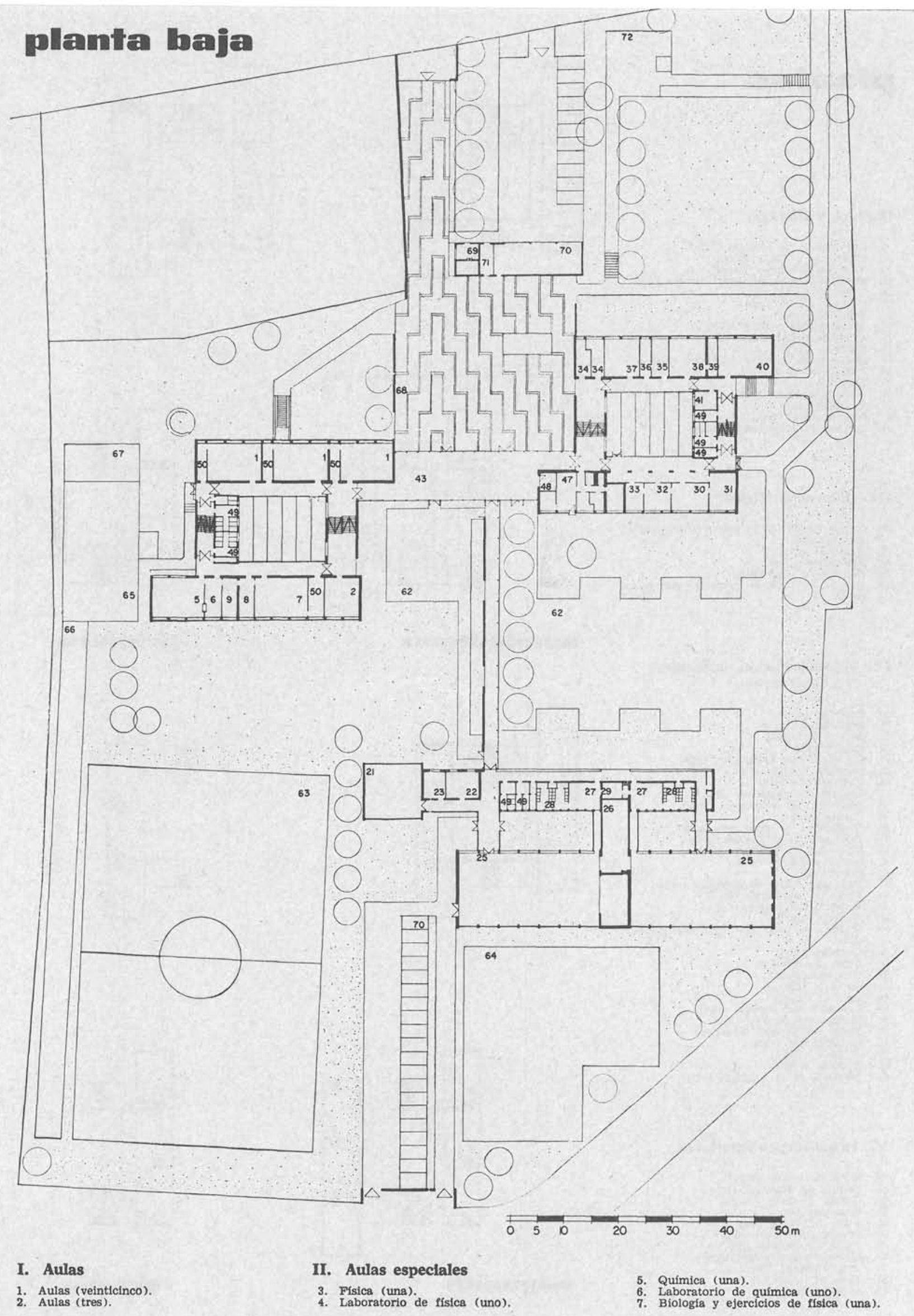




\section{plantas}

\section{Química y Biología}

8. Laboratorio de blologia (uno).

9. Museo de biología (uno).

1. Material para los trabajos manuales (ung).

2. Trabajos varios (una).

13. Sala de dibujo (una).

14. Despacho (uno).

5. Máquinas de escribir (dos).

16. Clase de cocina (una).

18. Despensa de la clase de cocina (dos).

9. Fregadero (uno).

19. Fregadero (uno).

1. Sala de música (una).

22. Ensayos (una)

24. Laboratorio fotográfico (uno).

\section{Educación física}

25. Gimnasios $13 \times 26 \mathrm{~m}$ (dos) (entre ambos, 26. un escenario).

27. Vestuarios (dos).

28. Cuartos de aseo (dos)

29. Habitación para el profesor, con sauna (una)

IV. Administración, economía y conservación

30. Director (una).

31. Subdirector (una).

32. Secretaría (uns).

33. Espera (una)

34. Coloquios con los padres (dos)

35. Consulta médica (una).

. Objetos de (uns).

.

profesores (una).

9. Cocin

40. Habitacion de profesores (uma).

Vestuario de profesores (uno).

. Biblioteca de alumnos (una).

Recreo cubierto (uno)

Vestibulo clases de conducir (uno).

Utiles de ensenaanza (una).

Vivienda del portero (una).

Portería (una).

. Cuartos de aseo para alumnos y profe-

sores.

Guardarropas.

1. Utiles de limpieza.

2. Bicicletas (una).

. Almacen (uno).

55. Lavadero del portero (uno).

56. Bodega del portero (una).

Taller del portero (uno)

. Instalaciones (una).

Cuadros (una).

61. Personal de la limpleza (una).

\section{Instalaciones exteriores}

62. Patio de recreo (uno).

63. Campo de deportes (uno).

64. Campo de juego (uno).

65. Gimnasio (uno).

66. Pista de ceniza (una).

7. Pruebas de saltos (uns).

8. Patio de entrada (uno).

9. Subestación eléctrica (una)

1. Aldones (uns).

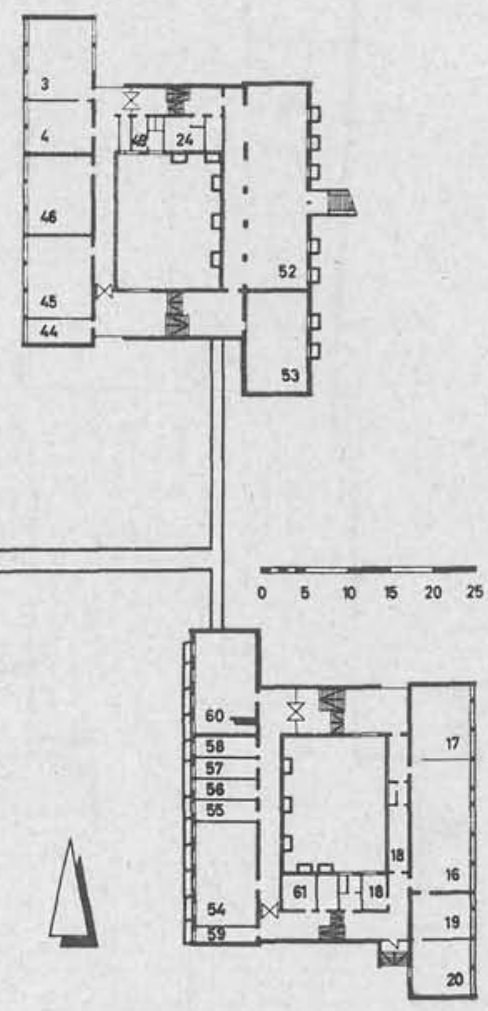

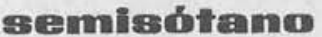

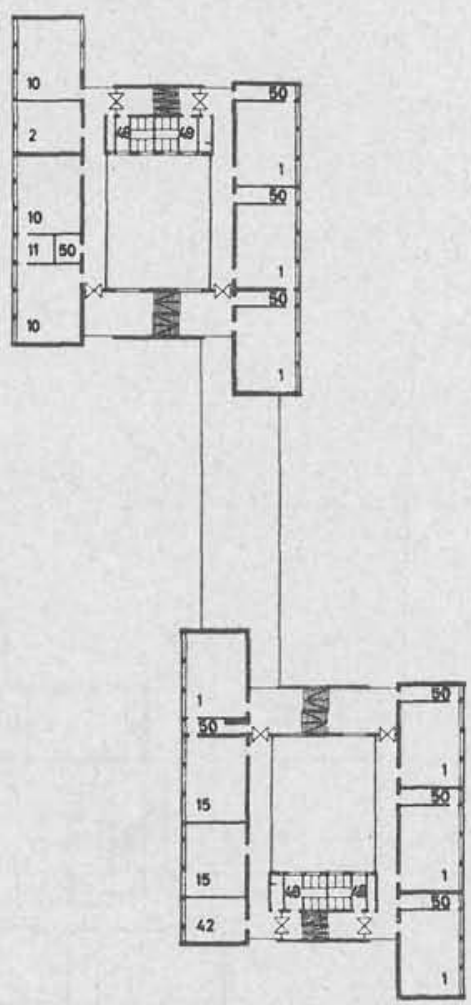

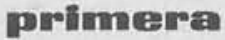

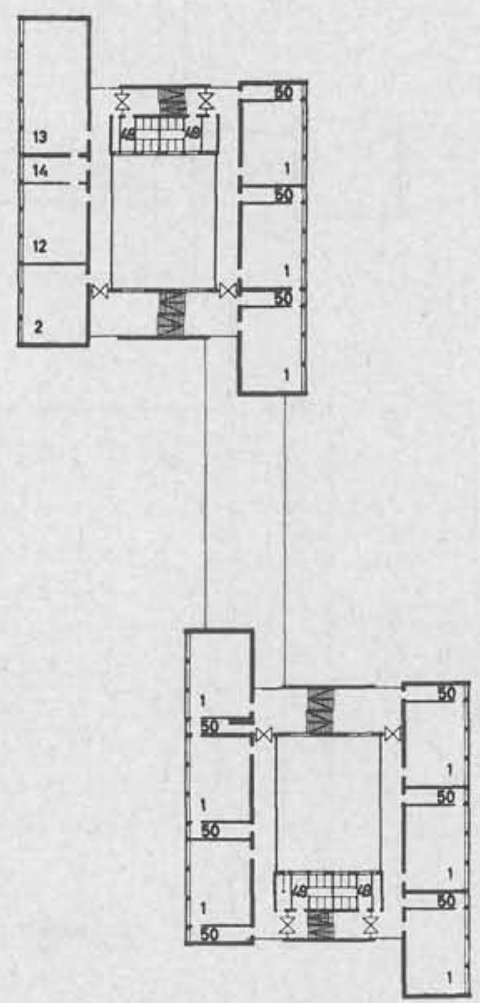

Begerumeda

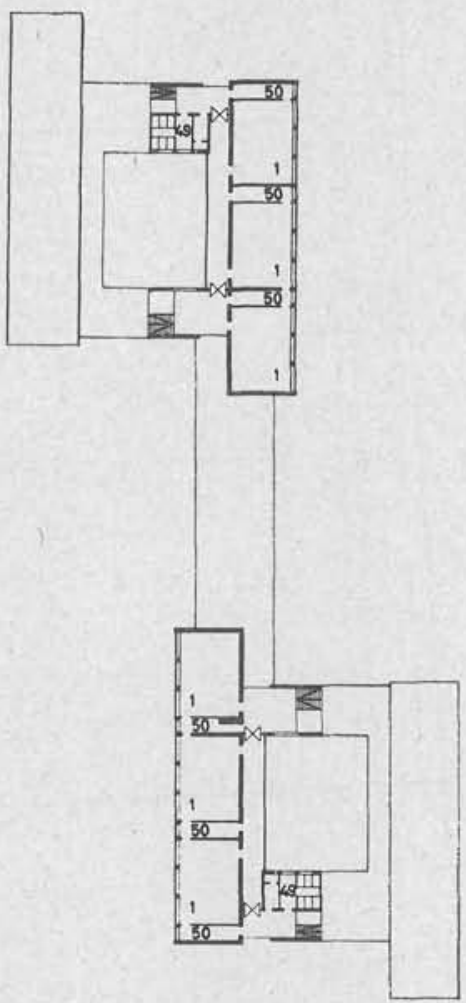

ㄱercerema 

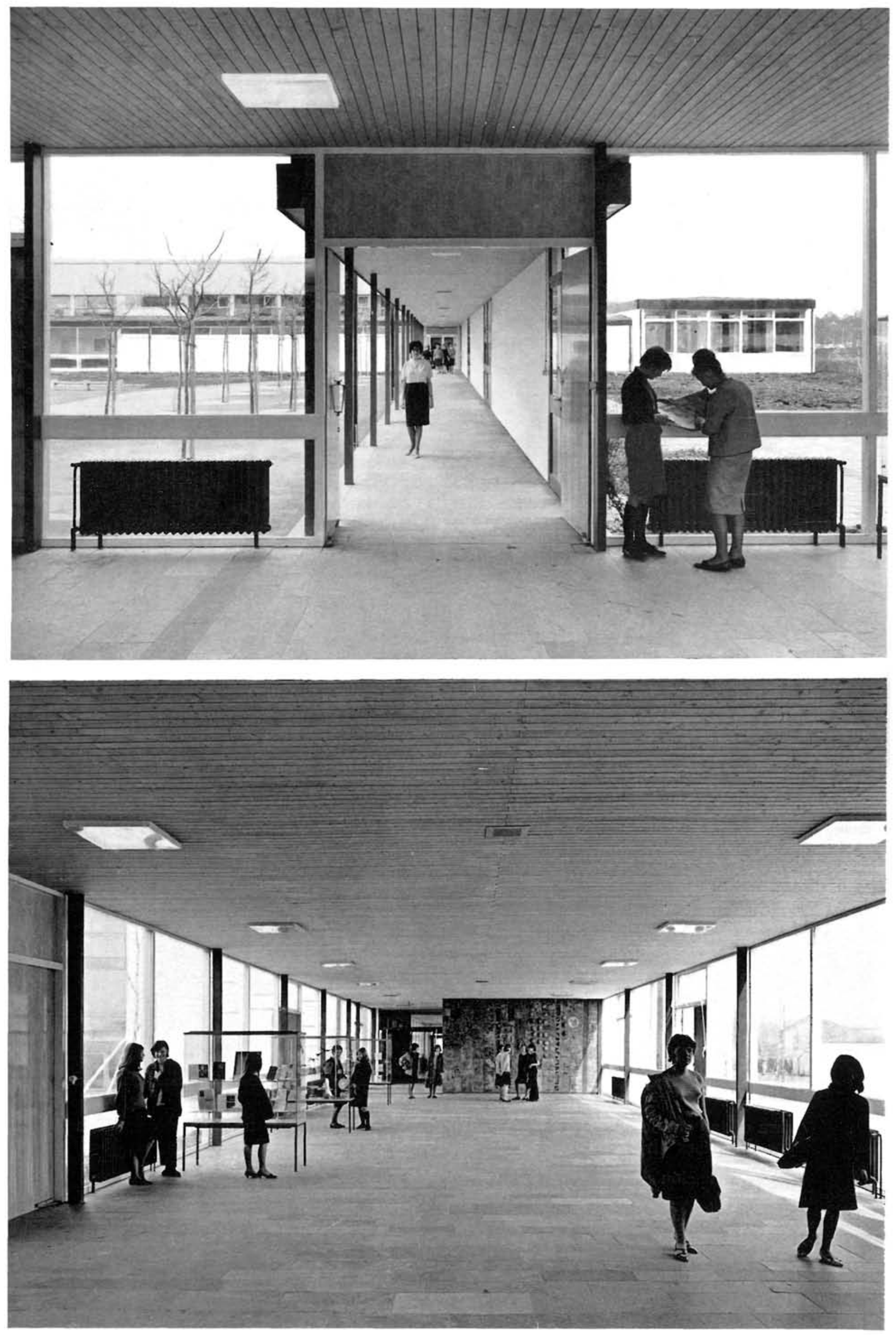


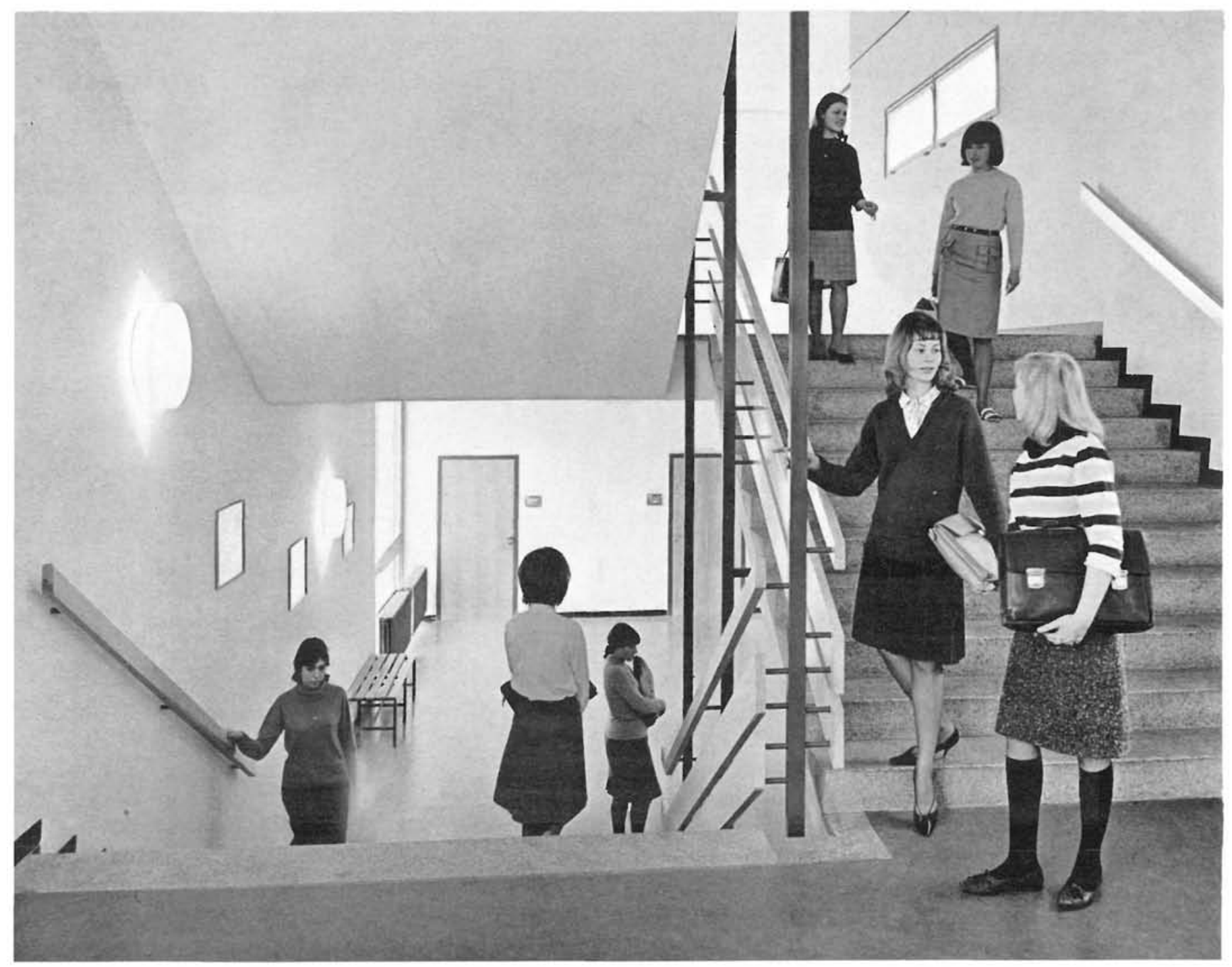

En la solución adoptada, de dividir la edificación principal en dos "cuerpos» de edificio, influyó el hecho de que por el centro del terreno corría una gran tubería de la red de aguas, lo que no aconsejaba la construcción en altura.

Para evitar que los bloques escolares tuvieran una gran longitud, fueron diseñados los grupos de clases alrededor de pequeños patios interiores.

Por la situación del terreno, resultaron las clases orientadas al este y al oeste.

La disposición de las escaleras facilitó diferentes alturas a los cuerpos edificados, dando origen a una silueta interesante. 
El desplazamiento de los precitados cuerpos y la posición de los garajes sirve para organizar el patio de entrada, el cual ofrece, como característica plástica, la original fuente, de recio y espontáneo aspecto.

El patio de recreo - entre los cuerpos de la escuela-, el campo de deportes y la conducción de agua determinaron la situación de los gimnasios.

El paso de unión entre ambos bloques marca una división clara de las diversas zonas, tanto respecto a utilización como en lo que se refiere a la urbanización del conjunto.

El pabellón de música, situado al final de dicho paso de unión, ocupa el centro de gravedad arquitectónico del conjunto.
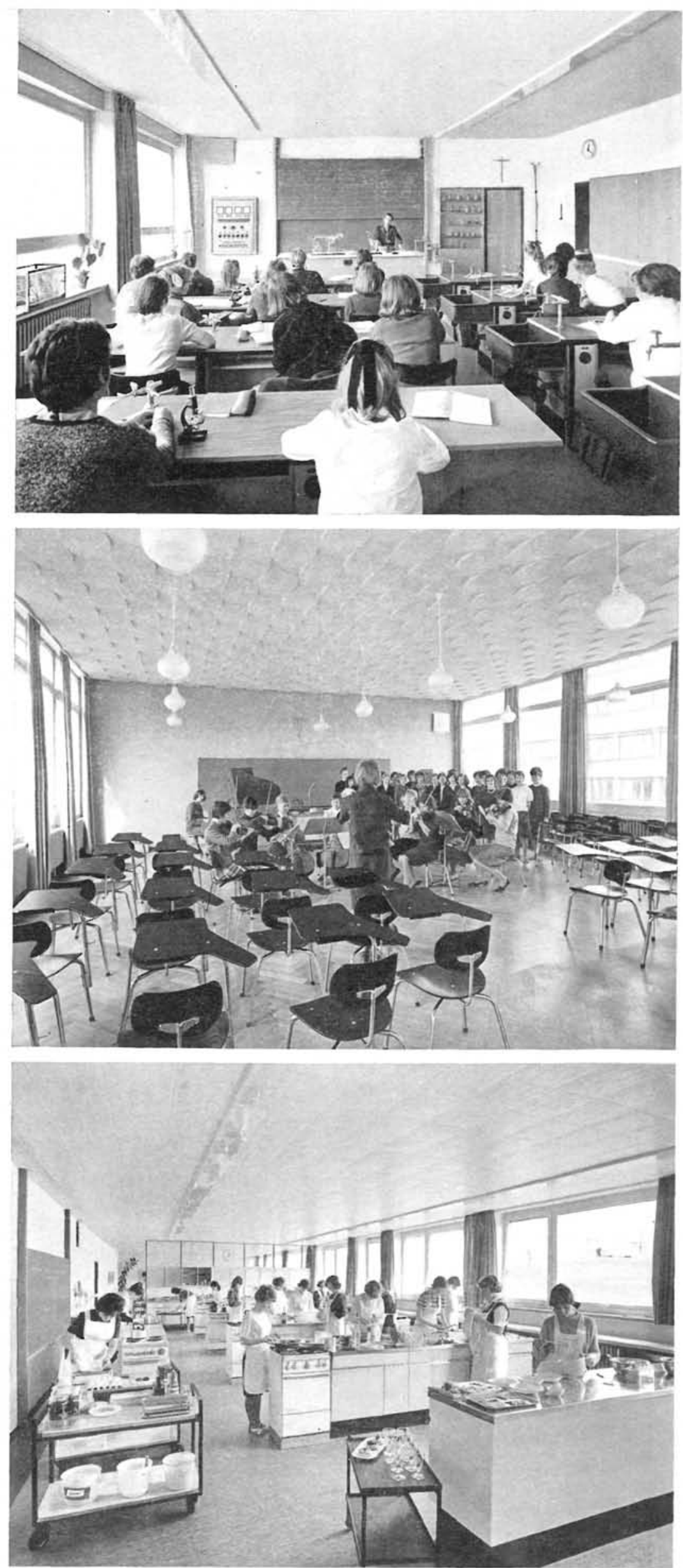
En cuanto a la ambientación interior, se ha logrado imprimir a todas las dependencias de la Escuela una atmósfera personal, y se han ordenado los espacios de manera extraordinariamente funcional y sencilla.

El arquitecto ha aprovechado al máximo las posibilidades de combinar masas de edificios y de crear volúmenes, habiendo conseguido plenamente que los intereses escolares sean tan importantes como los efectos arquitectónicos.

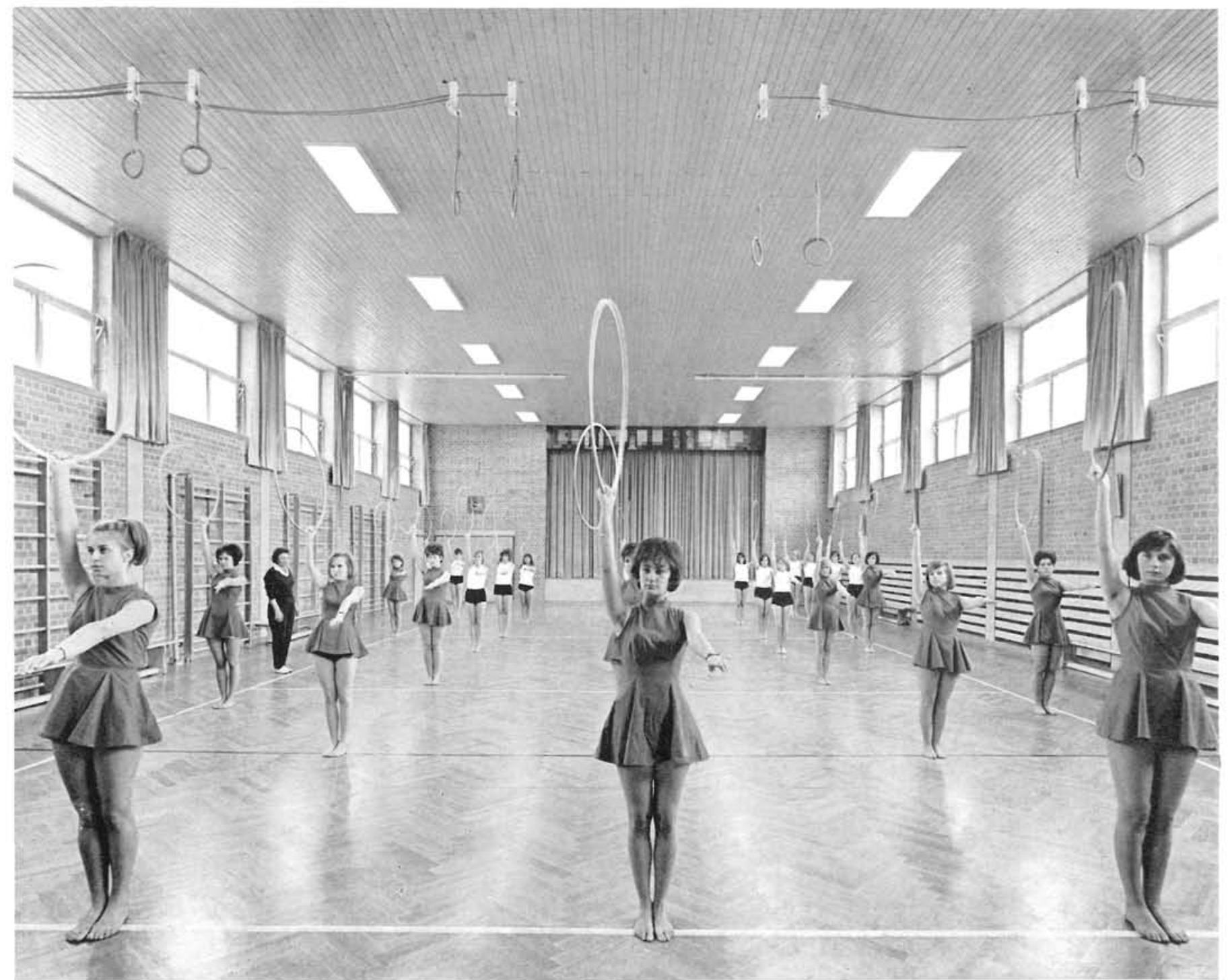




\title{
Eco
}

\author{
F. Haindl, architecte BDA
}

Formant un ensemble qui se détache du paysage urbain environnant, cette école se compose de deux édifices principaux dans lesquels se déroulent les classes, unis entre eux par une galerie couverte et un passage qui mène au pavillon de musique et un gymnase.

La cour de récréation et le terrain de sports déterminent la situation des gymnases.

Tous les détalls intérieurs, le jeu des volumes et leur organisation fonctionnelle ont collaboré efficacement à l'heureuse réalisation de cet intéressant établissement scolaire.

\section{Femalle secondary school in Mumichn, Eemanang}

F. Haindl, BDA architect

This school stands out visually from the surrounding urban landscape. The school consists of two buildings occupied by the classrooms, and connected to each other by an open pathway and a corridor, at the end of which there is a music room and gymnasium.

The position of the playing field and sports grounds is determined by the location of the gymnasium.

All internal details, the relative proportions of the built volumes and their functional organisation help to make this a most successfully designed school.

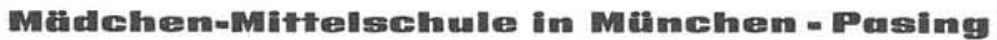

F. Haindl, Architekt BDA

Sie bildet einen Komplex unabhängig von der Nachbarschaft optisch. Er besteht aus zwei Baukörper in Verbindung durch einen gedeckten Gang.

Der Musikpavillon liegt am Ende des Verbidungsganges. Der Spielhof und der Sportplatz bestimm ten die Lage der Turnhallen.

Alle inneren Einzelheiten und seine Betriebeinrichtung geben einen besonderen Charakter dem Komplex. 